\title{
Tratamiento de la linfohistiocitosis hemofagocítica con células mesenquimatosas y linfocitos
}

- Carlos Enrique Sanabria Labrador

Cúcuta (Norte de Santander)

Introducción: la linfohistiocitosis hemofagocítica ( $\mathrm{HLH}$, por su sigla en inglés) es un síndrome clínico caracterizado por una severa inflamación sistémica con alta mortalidad incluso con tratamiento apropiado. Esta afección, que comparte características con sepsis y síndrome de respuesta inflamatoria sistémica (SRIS), es causada por la activación excesiva de linfocitos y macrófagos que producen altos niveles de citocinas. La HLH se asocia con muchas afecciones subyacentes y afecta todos los grupos de edad. Hace más de una década se están investigando las propiedades y los efectos sobre el sistema inmunológico de las células mesenquimatosas, encontrándose que no expresan proteínas para grupo sanguíneo solo HLA tipo l; los linfocitos pueden ser activados por estimulación electromagnética para poder modular su potencial efecto. El objetivo del trabajo es evaluar la efectividad de las células mesenquimatosas heterólogas y linfocitos autólogos activados para frenar la linfohistiocitosis hemofagocítica adquirida por enfermedades inmunológicas en ocho pacientes de sexo femenino.

Materiales y métodos: se toman muestras de médula de la paciente y de dos familiares, se someten a cultivos e hibridación; a las tres semanas se aplican células mesenquimatosas por vía intravenosa. Se toma a la semana muestra de sangre de la paciente, se separa capa de leucocitos, se somete a campos electromagnéticos por tres semanas y se aplica vía intravenosa.

Resultados: se hizo seguimiento por tres años, encontrándose que las pacientes permanecieron asintomáticas y con los respectivos paraclínicos dentro de rangos normales.

Conclusiones: existe la posibilidad de tratamiento para la linfohistiocitosis hemofagocítica con células mesenquimatosas y linfocitos activados. 